\title{
Influence of Single and Dual Mass Flywheel Usage in IC Engines on Clutch Dynamics
}

\author{
Emin Güllü ${ }^{1}$, Abdurrahman Y1lmaz ${ }^{2 *}$ \\ 0000-0001-9019-7617, 0000-0002-1300-8728
}

${ }^{1}$ Mechanical Engineering Department, Faculty of Engineering, Bursa Uludağ University, Bursa, 16059, Turkey
${ }^{2}$ Automotive Department, Zuhal Dörtçelik Şenipek Vocational High School, Bursa, 16010, Turkey

\begin{abstract}
The dual mass flywheel especially used in diesel engines has a structure in which the single- mass flywheel is divided into two parts and these two parts are combined with a curved helical spring. The flywheel is a part that reduces the speed fluctuations in the crankshaft of the internal combustion engines. In addition to this function, the dual mass flywheel dampens the torsional vibrations better than the clutch disc springs thanks to the spring system found in its structure. There are no torsional springs in the disc of the clutch system where dual mass flywheel is used. The dual mass flywheel is used with a rigid clutch disc without torsion springs. From this point of view, it is thought that the clutch dynamics of both systems are different. For this purpose, mathematical models of both systems were formed. The obtained models were solved after the appropriate transformations. As a result, it was seen the clutch engagement times are almost same in both systems. However in the clutch system where the dual mass flywheel is used the clutching process is performed more smoothly.
\end{abstract}

Keywords: Dual mass flywheel, clutch dynamics, torsional vibration, engine
* Corresponding author

Abdurrahman Yilmaz

yilmaz3426@gmail.com.tr

Adress: Automotive Department, Zuhal Dörţ̧elik Şenipek Vocational High School, Bursa, 16010, Turkey

Tel: +902243715499

Fax: +902243717689

Researh Article

Manuscript

Received 22.01.2020

Revised 07.04.2020

Accepted 19.04 .2020

Doi:10.30939/ijastech..678615

\section{Introduction}

The dual-mass flywheel (DMF) can generally be defined as single mass flywheel (SMF) divided into two parts. It consists of the first mass connected to the crankshaft and the second mass connected to the gearbox input shaft. Two independent flywheels were interconnected by a springdamper system consisting of curved helical springs. These masses were supported by the bearing or sliding bearing to be rotatable in mutually opposite directions. On the first mass of the flywheel, there is a ring gear that corresponds to the starter gear. The first mass cover together with the first mass of the flywheel forms the gap required for the circular spring channel. The helical springs having a curved form were fitted into the guides in the spring channels. The engine torque is transmitted via the drive flange. The drive flange has been firmly riveted to the second mass. The ears of flange fit between the spring channels of the first mass. The clutch system has been located on the second mass of the flywheel. The distributed assembly picture of the dual mass flywheel produced by Schaeffler-LuK firm is shown in Figure 1.

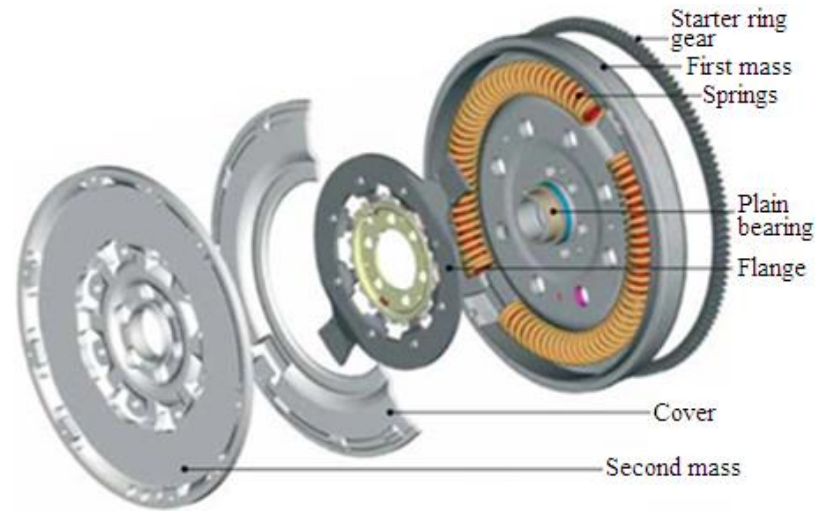

Fig. 1. Dual mass flywheel (Schaeffler-LuK) 


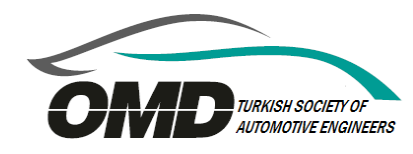

There are torsional damping springs on the clutch disc of the mechanical clutch system to protect the gearbox and other powertrain components from torsional vibrations caused by speed irregularities in the engine. These springs are inadequate to damp the torsional vibrations and vibrations pass into the gearbox. This situation results in resonance vibration, especially at low engine speeds. Resonance vibration causes noise and additional loads on the gearbox. Nowadays, manufacturers turn to engine designs that keep the engine's working range as wide as possible to reduce fuel consumption. This situation requires a flicker-free operation at low engine speeds. The dual-mass flywheel effectively damps torsional vibrations thanks to its spring-damper system and shifts the resonance rpm below idle speed. It is seen on the top of Figure 2 that single mass flywheel, clutch pressure plate and clutch disc used in an automobile. However, it is seen on the under of Figure 2 that the dual mass flywheel, clutch pressure plate and clutch disc which used on the same vehicle. It is noteworthy that there are no torsion springs in the disc of the clutch system which is used together with the dual mass flywheel. The springs of DMF perform the task of disc torsion springs in the classical system more effectively.

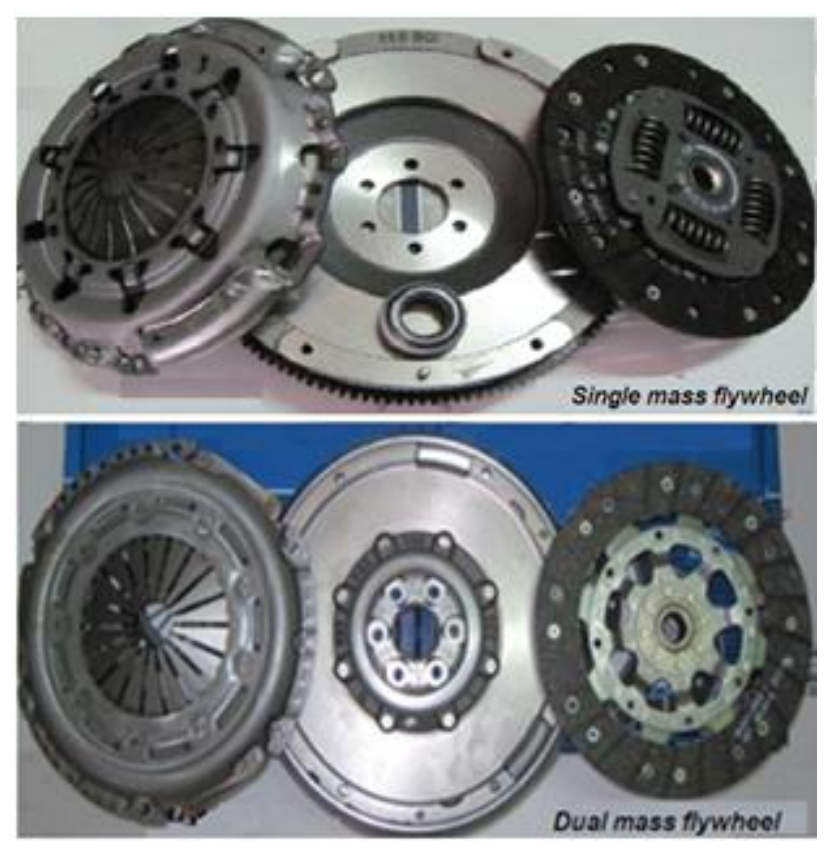

Fig. 2. Clutch system parts used together with single and dualmass flywheels

When the studies in the literature are examined it is seen that the studies about the dynamic of the classical clutch system which is used SMF. It was not encountered in literature a study about the clutch dynamic of the system which is used DMF. Karadere et al. [1] had examined the dynamic phenomena during the engagement of the clutch, taking into account the clutch springs and system flexibility. They have created a four degree of freedom nonlinear model based on two different scenarios for clutch and accelerator pedal movements. Using this model, they have analyzed the effects of various system parameters such as stiffness, inertia, friction gradient, viscous damping on the clutch dynamics. Gaillard and Singh [2] have examined the dynamic characteristics of torsional vibration of a vehicle clutch with the help of linear and nonlinear models containing five different parameters. It is also examined dynamic hysteresis curves in this study. The authors have created two different models as static and dynamic. They have shown that the noise level in gear rattling is calculated lower in static. Sawanobori and Suehiro [3] have examined clutch induced shake (judder). They showed that two major reasons for this situation are the speed changes in clutch and montage errors in driveline. They had given a simulation method to examine the effects of these two causes separately on the judder event. Centea et al. [4] have made a nonlinear dynamic analysis related to the effects of different clutch pad materials on the judder event. Crowther et al. [5] have presented in their study that clutch judder is related to the coefficient of friction by using a method called stability analysis and they confirmed this information with numerical simulations. They developed an algorithm that modeled the stick-slip behavior of the clutch and used this algorithm in numerical simulations. Numerical simulations show that the probability of stick-slip increases with clutch pressure irregularities and external moment irregularities. Jadhav [6] has made a study related to the optimization of gearwheels and clutch damper springs to eliminate gear rattling noise in the gearbox. For reducing the transmission of engine vibrations to the gearbox torsional vibrations of the gearbox have measured and these data have analyzed to select the most appropriate clutch damper.

In this study, mathematical model of power transmission svstems using single and dual mass flvwheels is solved in Matlab $\circledast$ program, and clutching process of both systems is compared according to different gear loads. In contrast to the studies in the literature, the clutching process of the power transmission system which is used DMF was also examined. This study is a continuation of the study comnaring the resonance hehavior of nower transmission systems using DMF and SMF by Güllü et al. [7]. A similar analysis method was followed and the same parametric data were used.

\section{Equations of motion}

Two separate models have been created for power transmission systems which are used SMF and DMF. 
These models include flywheel, clutch system, gearbox and close parts (differential and axles for a front-wheeldrive vehicle). The power transmission system which is used SMF is shown in Figure 3.

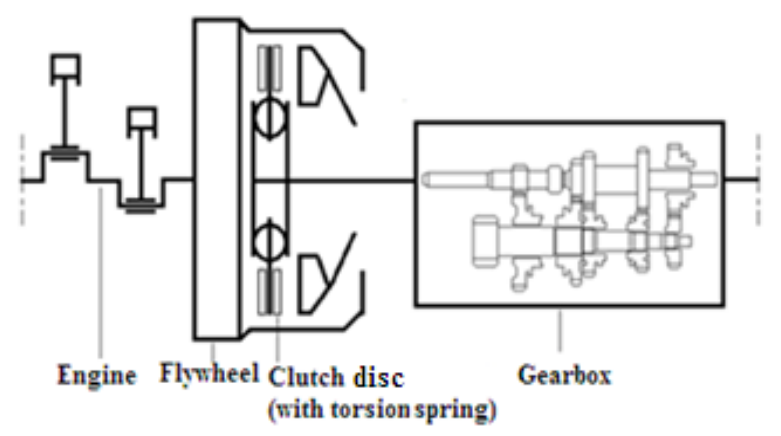

Fig. 3. Power transmission system using a single mass flywheel

The power transmission system which is used DMF is shown in Figure 4.

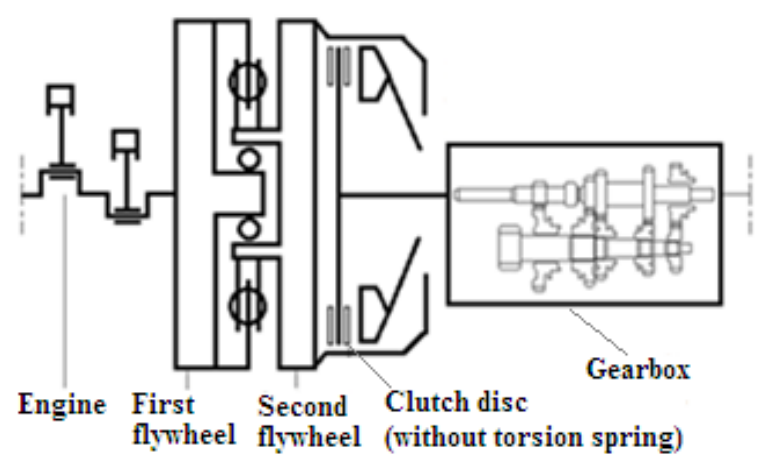

Fig. 4. Power transmission system using a dual mass flywheel

The clutch disc of the power transmission system which is used SMF has torsional springs. However, the power transmission system which is used DMF has a more rigid clutch disc without torsional springs. The springs between two masses of DMF replace the torsion springs in the clutch disc. The mathematical model of the system which is used SMF is shown in Figure 5. This model is generated from Figure 3 and the model which is used in the study of Karadere et al. [1]

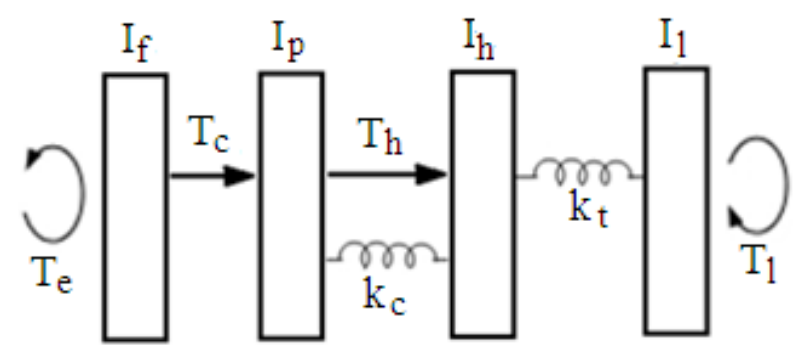

Fig. 5. The mathematical model of the system using SMF
Similarly, the mathematical model of the system which is used DMF is shown in Figure 6.

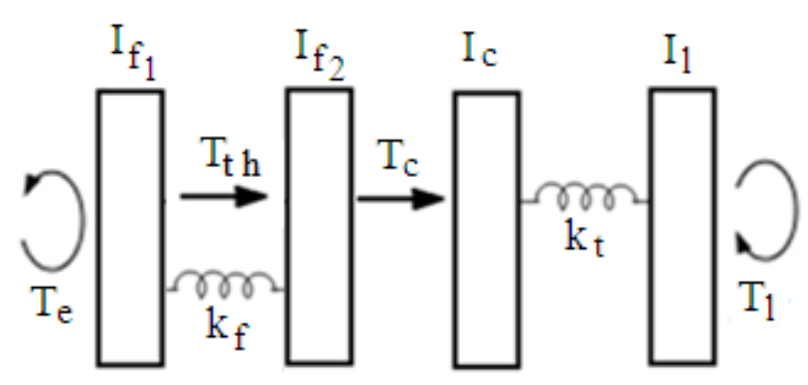

Fig. 6. The mathematical model of the system using DMF

The elements of the power transmission system are thought of as discs connected by springs in these models. $T_{e}$ is the engine torque. $T_{h}$ is the torque that is caused by friction elements placed between cushion spring plate and disc hub to suppress torsional vibrations. $T_{l}$ is the load torque. In other words, it is the torque of the power transmission system parts reduced to the clutch output. $T_{t h}$ is the damping moment caused by the hysteresis of the springs between the masses of DMF. According to He et al. [8], the value of this moment is receivable $25 \mathrm{Nm}$ for $1000 \mathrm{rpm}$ engine speed. $T_{c}$ is the torque due to the surface friction of the flywheel and the clutch disc. $T_{c}$ can be expressed as follows.

$T_{c}=R N\left(\mu_{0}+c R\left|\dot{q}_{f}-\dot{q}_{p}\right|\right)$

$R$ is the averaged radius of distributed friction forces. $N$ is the normal force supplied by diaphragm spring. $\mu_{0}$ is the constant component of friction coefficient. $c$ is the friction gradient varying proportional to the magnitude of relative linear speed. If , I $p$ and $I h$ denote the mass moments of inertia of the flywheel, clutch disc pad and disc hub in the classical power transmission system respectively. If 1 and If 2 mean respectively the mass moments of inertia of the first and second mass of the dual mass flywheel. Ic is the mass moment of inertia of the clutch disc of the power transmission system which is used DMF. $I l$ is the mass moment of inertia reduced to the clutch output of the power transmission system parts. This parameter changes in different gears. $k_{t}$ is equivalent stiffness of the gearbox input shaft in both systems. $k_{c}$ is equivalent stiffness of torsion springs on the clutch disc of the power transmission system which is used SMF. $k_{f}$ represents the equivalent stiffness of springs which are located between masses of DMF. $\eta_{t}$ represents the viscous damping coefficient in the gearbox. The expression $q$ in above equation and following equation sets represent the angular displacements of elements in the models.

The equations of motion of the power transmission system which is used SMF were generated as following from Figure 5. 
$I_{f} \ddot{q}_{f}+T_{c} \operatorname{sgn}\left(\dot{q}_{f}-\dot{q}_{p}\right)-T_{e}=0$

$I_{p} \ddot{q}_{p}-T_{c} \operatorname{sgn}\left(\dot{q}_{f}-\dot{q}_{p}\right)+k_{c}\left(q_{p}-q_{h}\right)+$

$+T_{h} \operatorname{sgn}\left(\dot{q}_{p}-\dot{q}_{h}\right)=0$

$I_{h} \ddot{q}_{h}-T_{h} \operatorname{sgn}\left(\dot{q}_{p}-\dot{q}_{h}\right)-k_{c}\left(q_{p}-q_{h}\right)$

$+k_{t}\left(q_{h}-q_{l}\right)++\eta_{t}\left(\dot{q}_{h}-\dot{q}_{l}\right)=0$

$I_{l} \ddot{q}_{l}-k_{t}\left(q_{h}-q_{l}\right)-\eta_{t}\left(\dot{q}_{h}-\dot{q}_{l}\right)+T_{l}=0$

The sgn (signum) function is used to determine the direction of the transmitted moment.

The above set of the equation is the second order. This set of equation will be solved numerically by the 4th order

Runge-Kutta method. In the Runge-Kutta method, the order of the equation is reduced to the first order.

First, the angular displacements of each element are numbered as follows.

$q_{f}=q_{1}$

$q_{p}=q_{2}$

$q_{h}=q_{3}$

$q_{l}=q_{4}$

By taking the first derivative of angular displacements, the angular velocity of each element is obtained as follows.

$\dot{q}_{f}=\dot{q}_{1}=q_{5}$

$\dot{q}_{p}=\dot{q}_{2}=q_{6}$

$\dot{q}_{h}=\dot{q}_{3}=q_{7}$

$\dot{q}_{l}=\dot{q}_{4}=q_{8}$

As a result of the transformations, the following first-order equation set consisting of 8 equations is obtained

$\dot{q}_{1}=q_{5}$

$\dot{q}_{2}=q_{6}$

$\dot{q}_{3}=q_{7}$

$\dot{q}_{4}=q_{8}$

$\dot{q}_{5}=\frac{-\left[\operatorname{sgn}\left(q_{5}-q_{6}\right) T_{c}-T_{e}\right]}{I_{f}}$

$\dot{q}_{6}=\frac{-\left[\begin{array}{c}-\operatorname{sgn}\left(q_{5}-q_{6}\right) T_{c}+k_{c}\left(q_{2}-\theta_{3}\right) \\ +T_{h} \operatorname{sgn}\left(q_{6}-q_{7}\right)\end{array}\right]}{I_{p}}$

$\dot{q}_{7}=\frac{-\left[\begin{array}{c}-k_{c}\left(q_{2}-q_{3}\right)-T_{h} \\ +k_{t}\left(q_{3}-q_{4}\right)+\eta_{t}\left(q_{7}-q_{8}\right)\end{array}\right]}{I_{h}}$

$\dot{q}_{8}=\frac{-\left[-k_{t}\left(q_{3}-q_{4}\right)-\eta_{t}\left(q_{7}-q_{8}\right)+T_{l}\right]}{I_{l}}$

Similarly, the equations of motion of the power transmission system which is used DMF were generated as following from Figure 6.

$$
\begin{aligned}
& I_{f_{1}} \ddot{q}_{f_{1}}+k_{f}\left(q_{f_{1}}-q_{f_{2}}\right)+T_{t h} \operatorname{sgn}\left(\dot{q}_{f_{1}}-\dot{q}_{f_{2}}\right)-T_{e}=0 \\
& I_{f_{2}} \ddot{q}_{f_{2}}+T_{c} \operatorname{sgn}\left(\dot{q}_{f_{2}}-\dot{q}_{c}\right)-k_{f}\left(q_{f_{1}}-q_{f_{2}}\right)- \\
& -T_{t h} \operatorname{sgn}\left(\dot{q}_{f_{1}}-\dot{q}_{f_{2}}\right)=0 \\
& I_{c} \ddot{q}_{c}+k_{t}\left(q_{h}-q_{l}\right)+\eta_{t}\left(\dot{q}_{c}-\dot{q}_{l}\right)- \\
& -T_{c} \operatorname{sgn}\left(\dot{q}_{f_{2}}-\dot{q}_{c}\right)=0 \\
& I_{l} \ddot{q}_{l}-k_{t}\left(q_{c}-q_{l}\right)-\eta_{t}\left(\dot{q}_{c}-\dot{q}_{l}\right)+T_{l}=0
\end{aligned}
$$

By using the Runge-Kutta method as above the following first-order equation set consisting of 8 equations is obtained

$\dot{q}_{1}=q_{5}$

$\dot{q}_{2}=q_{6}$

$\dot{q}_{3}=q_{7}$

$\dot{q}_{4}=q_{8}$

$\dot{q}_{5}=\frac{-\left[k_{f}\left(q_{1}-q_{2}\right)+T_{t h} \operatorname{sgn}\left(q_{5}-q_{6}\right)-T_{e}\right]}{I_{f_{1}}}$

$\dot{q}_{6}=\frac{-\left[\operatorname{sgn}\left(q_{6}-q_{7}\right) T_{c}-k_{f}\left(q_{1}-q_{2}\right)-T_{t h} \operatorname{sgn}\left(q_{5}-q_{6}\right)\right]}{I_{f_{2}}}$

$\dot{q}_{7}=\frac{-\left[-\operatorname{sgn}\left(q_{6}-q_{7}\right) T_{c}+k_{t}\left(q_{3}-q_{4}\right)+\eta_{t}\left(q_{7}-q_{8}\right)\right]}{I_{c}}$

$\dot{q}_{8}=\frac{-\left[-k_{t}\left(q_{3}-q_{4}\right)-\eta_{t}\left(q_{7}-q_{8}\right)+T_{l}\right]}{I_{l}}$

\section{Numerical results}

In this section, it is presented that the analysis results which are obtained by using parametric data which belongs to a vehicle that is nowadays produced. The same parametric data was also used in the study of Güllü et al. [7]. Table 1 shows the parametric data common to both systems.

Table 1. Parametrical data common to both systems

\begin{tabular}{c|l|l}
\hline $\begin{array}{c}\text { Averaged radius of clutch } \\
\text { disc }\end{array}$ & $R$ & $0,10809 \mathrm{~m}$ \\
\hline $\begin{array}{c}\text { Constant of friction } \\
\text { coefficient }\end{array}$ & $\mu_{0}$ & 0,25 \\
\hline $\begin{array}{c}\text { Friction gradient } \\
\begin{array}{c}\text { Stiffness of the gearbox in- } \\
\text { put shaft }\end{array}\end{array}$ & $k_{t}$ & $20305 \mathrm{Nm} / \mathrm{rad}$ \\
\hline $\begin{array}{c}\text { Viscous damping } \\
\text { coefficient in the gearbox. }\end{array}$ & $\eta_{t}$ & 0,05 \\
\hline
\end{tabular}


Table 2 shows the parametric data of the system which is used SMF.

Table 2. Parametric data of power transmission system which is used SMF

\begin{tabular}{c|l|l}
\hline Inertia of the flywheel & $I_{f}$ & $0,175 \mathrm{kgm}^{2}$ \\
\hline Inertia of the clutch pad & $I_{p}$ & $0,004 \mathrm{kgm}^{2}$ \\
\hline Inertia of the clutch hub & $I_{h}$ & $0,0024 \mathrm{kgm}^{2}$ \\
\hline $\begin{array}{c}\text { Stiffness of clutch disc } \\
\text { springs }\end{array}$ & $k_{c}$ & $367 \mathrm{Nm} / \mathrm{rad}$ \\
\hline
\end{tabular}

Table 3 shows the parametric data of the system which is used DMF.

Table 3. Parametric data of power transmission system which is used DMF

\begin{tabular}{c|l|l}
\hline $\begin{array}{c}\text { Inertia of the first mass } \\
\text { of DMF }\end{array}$ & $I_{f 1}$ & $0,135 \mathrm{kgm}^{2}$ \\
\hline $\begin{array}{c}\text { Inertia of the second } \\
\text { mass of DMF }\end{array}$ & $I_{f 2}$ & $0,045 \mathrm{kgm}^{2}$ \\
\hline $\begin{array}{c}\text { Inertia of the clutch disc } \\
\text { used with DMF }\end{array}$ & $I_{c}$ & $0,0064 \mathrm{kgm}^{2}$ \\
\hline $\begin{array}{c}\text { Stiffness of DMF } \\
\text { springs }\end{array}$ & $k_{f}$ & $68 \mathrm{Nm} / \mathrm{rad}$ \\
\hline
\end{tabular}

Table 4 shows for different gear loads the moments of mass inertia reduced to the clutch output of power transmission system parts and for different gear loads the load torques.

Table 4. For different gears the moments of mass inertia and the load torques

\begin{tabular}{l|l|l|l|l}
\hline 1.gear & $I_{l l g}$ & $0,00118 \mathrm{kgm}^{2}$ & $T_{l l g}$ & $2 \mathrm{Nm}$ \\
\hline 2. gear & $I_{l 2 g}$ & $0,0281 \mathrm{kgm}^{2}$ & $T_{l 2 g}$ & $4,18 \mathrm{Nm}$ \\
\hline 3. gear & $I_{l 3 g}$ & $0,0549 \mathrm{kgm}^{2}$ & $T_{l 3 g}$ & $10,55 \mathrm{Nm}$ \\
\hline 4. gear & $I_{l 4 g}$ & $0,111 \mathrm{kgm}^{2}$ & $T_{l 4 g}$ & $4,25 \mathrm{Nm}$ \\
\hline 5. gear & $I_{l 5 g}$ & $0,198 \mathrm{kgm}^{2}$ & $T_{l 5 g}$ & $65 \mathrm{Nm}$ \\
\hline
\end{tabular}

It is understood from the values in Table 4 that the load inertia and moment increases as the gear increases.

The engine torque $T e$ is shaped by the changes in accelerator pedal movement. At the same time the normal force $N$ is also shaped by with the changes in clutch pedal movement.

As Karadere et al. [1] the following scenario was used for engine torque. Tes is engine torque at the start of clutch engagement and its value is taken as $50 \mathrm{Nm}$. Tef is engine torque at the end of clutch engagement and its value is taken as $100 \mathrm{Nm}$. te is the time elapsed between the start and end moments and its value is taken as 0,57 second.
Thus depending on the clutch engagement time, the engine torque is calculated by the following correlation

$T_{e}=T_{e s}+\frac{\left(T_{e f}-T_{e s}\right) t}{t_{e}}$

As Karadere et al. [1] the following scenario was used for normal force. Fs is the normal force at the time the gap between the pressure plate and the disc closes and its value is taken as $1250 \mathrm{~N}$. Ff is maximum normal force acting on pressure plate and its value is taken as $4000 \mathrm{~N}$. $t c$ is the time spent until the normal force rises from $F s$ to $F f$ and its value is taken as 0,54 second.

Thus depending on the clutch engagement time, the normal force is calculated by the following correlation

$$
N=F_{S}+\frac{\left(F_{f}-F_{S}\right) t}{t_{c}}
$$

Figure 7 shows the results of the clutch dynamic of systems that are used SMF and DMF in first gear. It is seen that the clutch engagement times are approximately the same in both systems. However speed oscillations which are after the first contact between the elements are less in the system which is used DMF.

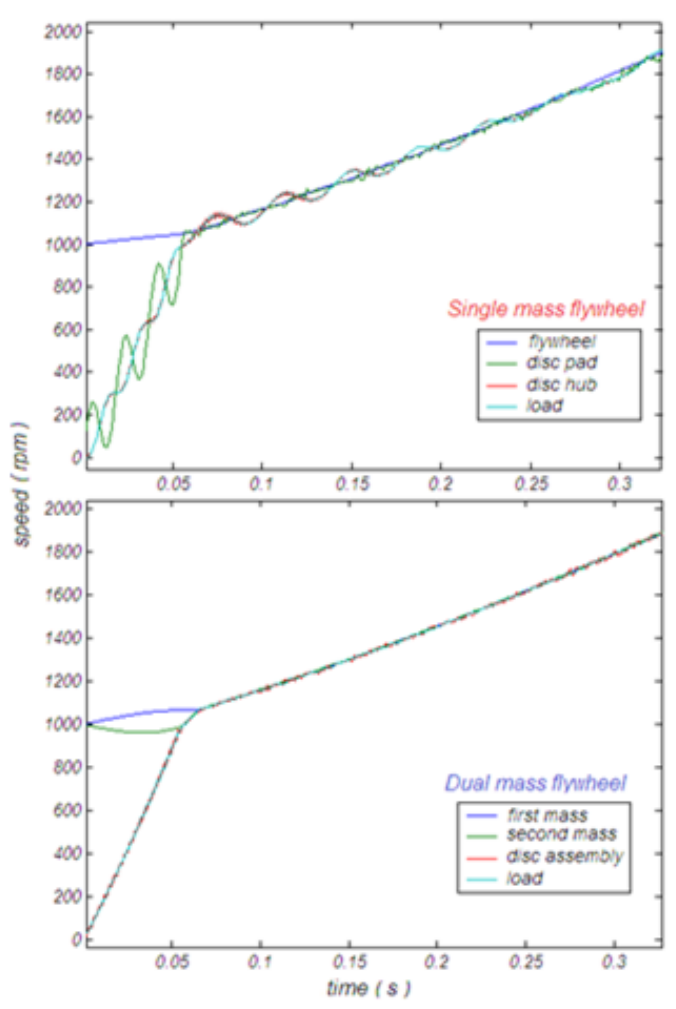

Fig.7. Clutch dynamic results in first gear 
Figure 8 shows the results of the clutch dynamic of systems that are used SMF and DMF in second gear.

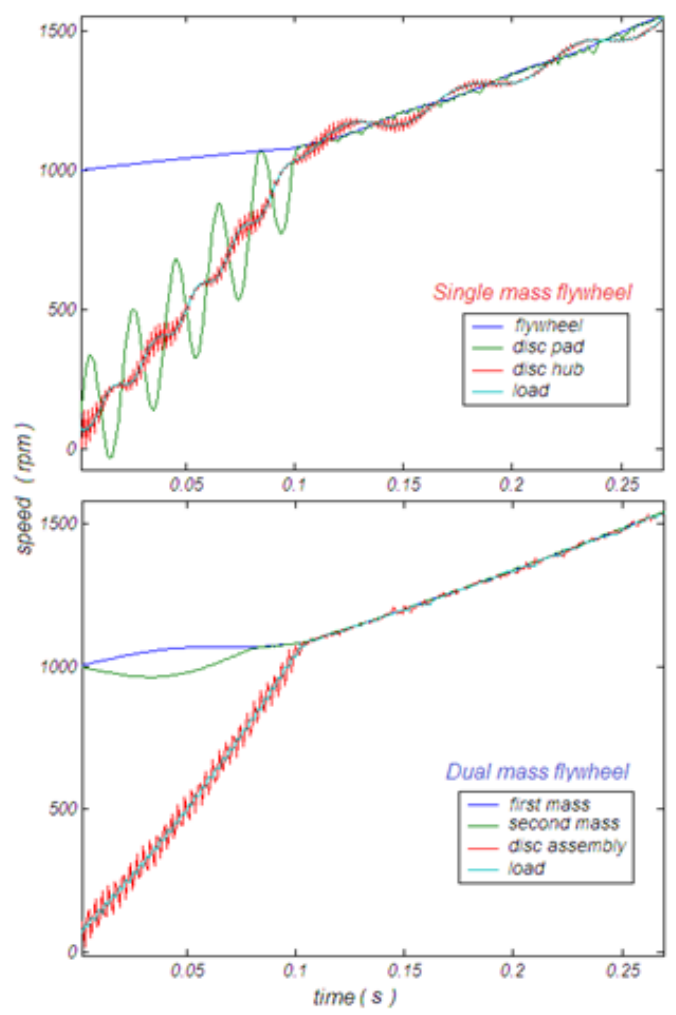

Fig.8. Clutch dynamic results in second gear

Engagement times are the same in both systems and approximately $0,1 \mathrm{sec}$. Engagement times increase compared first gear $0,04 \mathrm{sec}$. Speed oscillations are more high in SMF.

Figure 9 shows the results of the clutch dynamic of systems that are used SMF and DMF in third gear.

Engagement times are the same in both systems and approximately $0,1 \mathrm{sec}$. Engagement times increase compared first gear $0,04 \mathrm{sec}$. Speed oscillations are more high in SMF.

Figure 10 shows the results of the clutch dynamic of systems that are used SMF and DMF in fourth gear. Engagement times are the same in both systems and approximately $0,3 \mathrm{sec}$. Engagement times increase compared second gear $0,14 \mathrm{sec}$. Speed oscillations are more high in SMF.
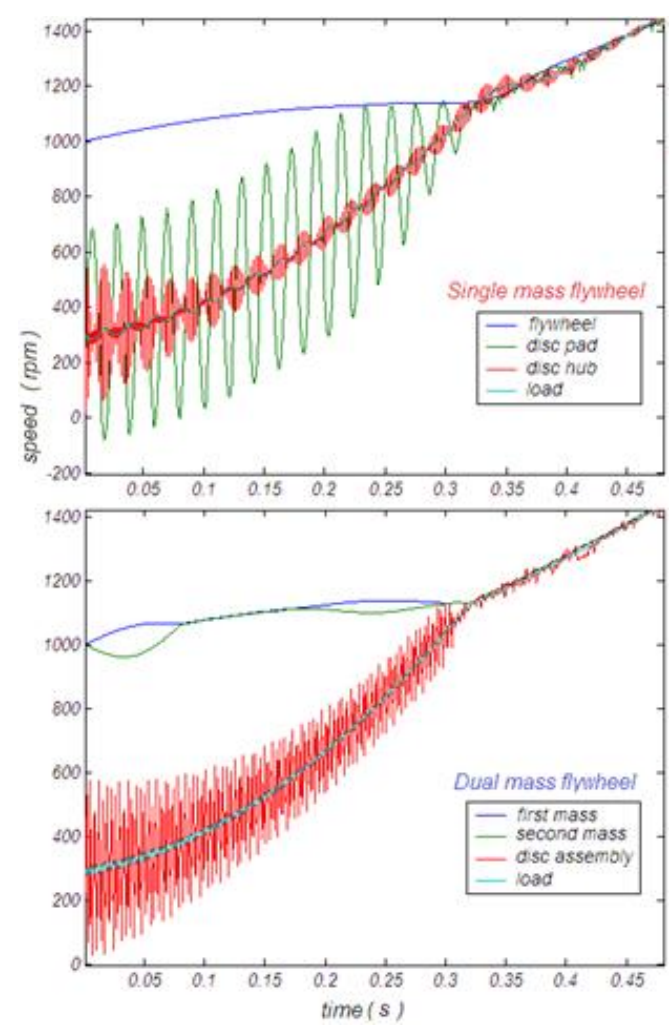

Fig.9. Clutch dynamic results in third gear

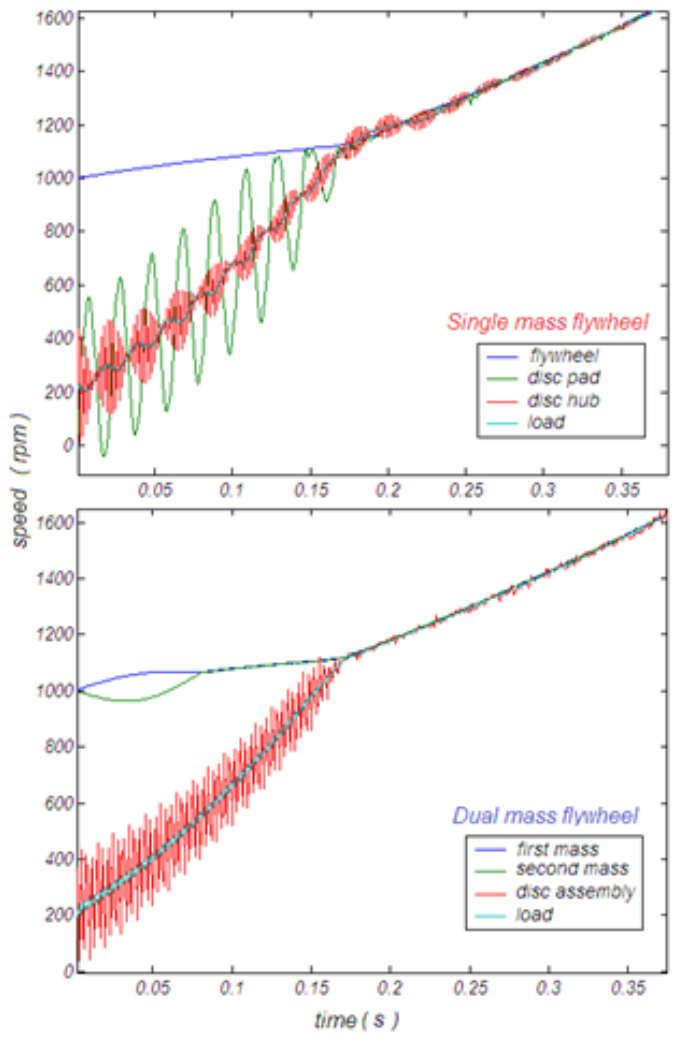

Fig.10. Clutch dynamics results in fourth gear 


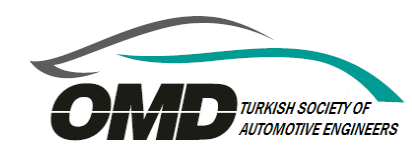

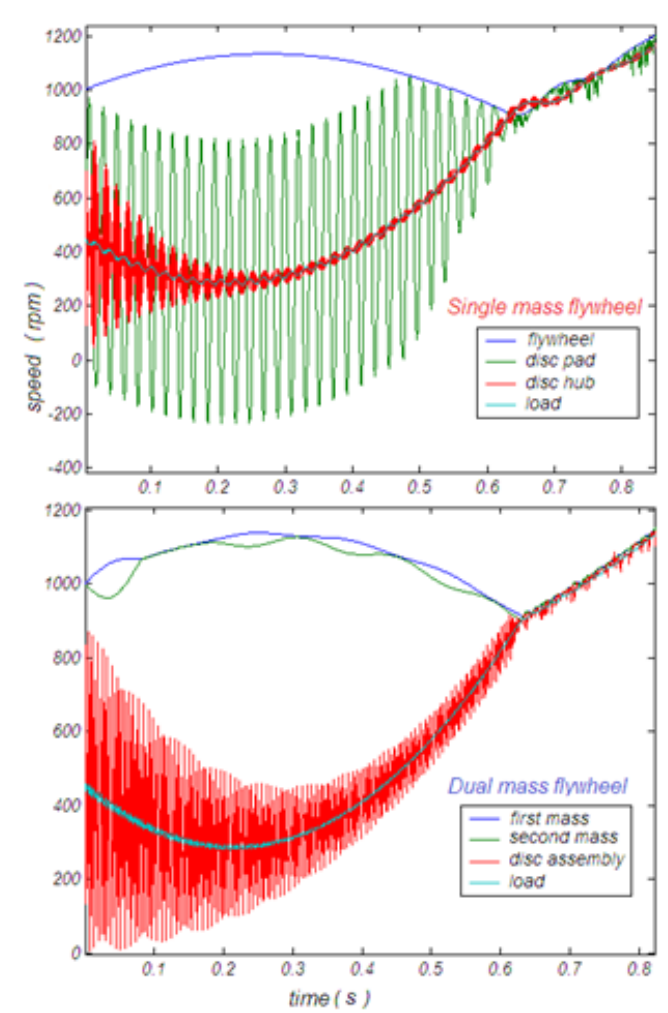

Fig.11. Clutch dynamic results in fifth gear

Figure 11 shows the results of the clutch dynamic of systems that are used SMF and DMF in fifth gear. Engagement times are the same in both systems and approximately 0,65 sec. Engagement times increase compared second gear $0,35 \mathrm{sec}$. Speed oscillations are more high in SMF.

It is seen that the clutch engagement times are approximately the same in both systems and increase due to increasing gear. The speed oscillations which are after the first contact between the elements are less in the system which is used DMF. This shows that the operation of the clutch system which is used DMF is more smooth and more regular than the classical clutch system. Because DMF springs absorb better the vibrations compared to the disc springs in the conventional system. The speed oscillations between the first and second masses of DMF which are interconnected by springs and flange are very few. Thus it is understood that the clutch operation in the system which is used DMF occurs between the clutch disc and load.

When all data are equal except load inertia, the changes in the clutch dynamic of the system which is used SMF are seen in Figure 12.

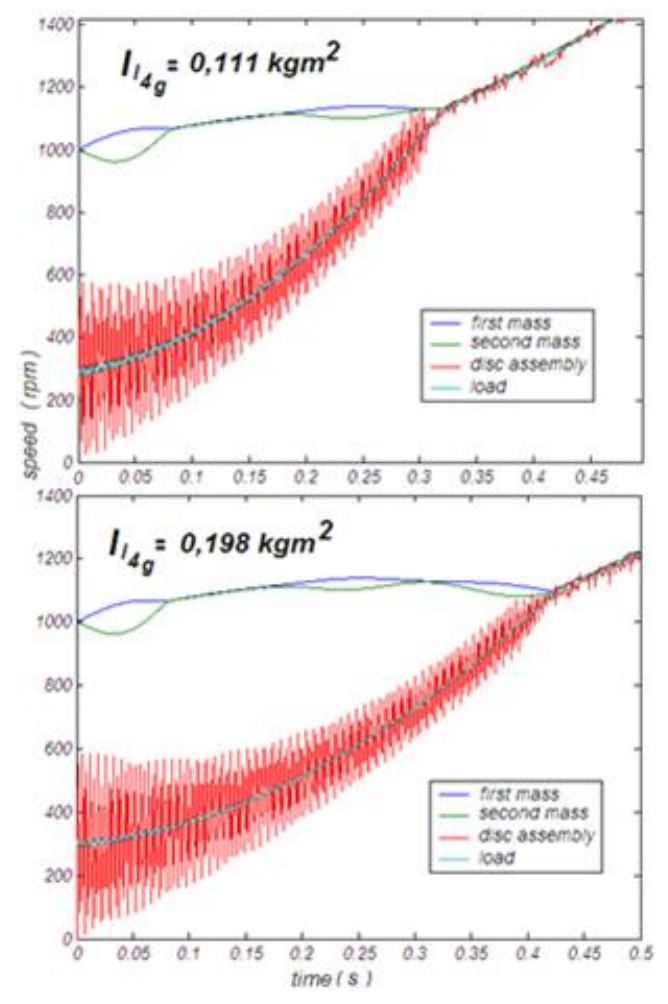

Fig.12. The effect of change in load inertia on the clutch dynamic of the system which is used SMF

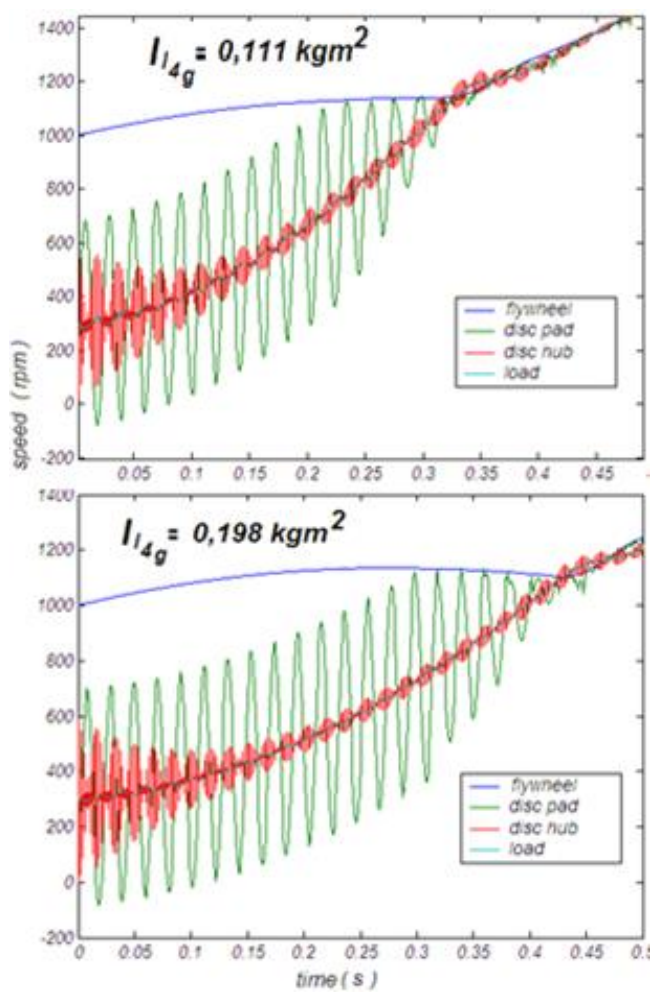

Fig.13. The effect of change in load inertia on the clutch dynamic of the system which is used DMF 
When all data are equal except load inertia, the changes in the clutch dynamic of the system which is used DMF are seen in Figure 13.

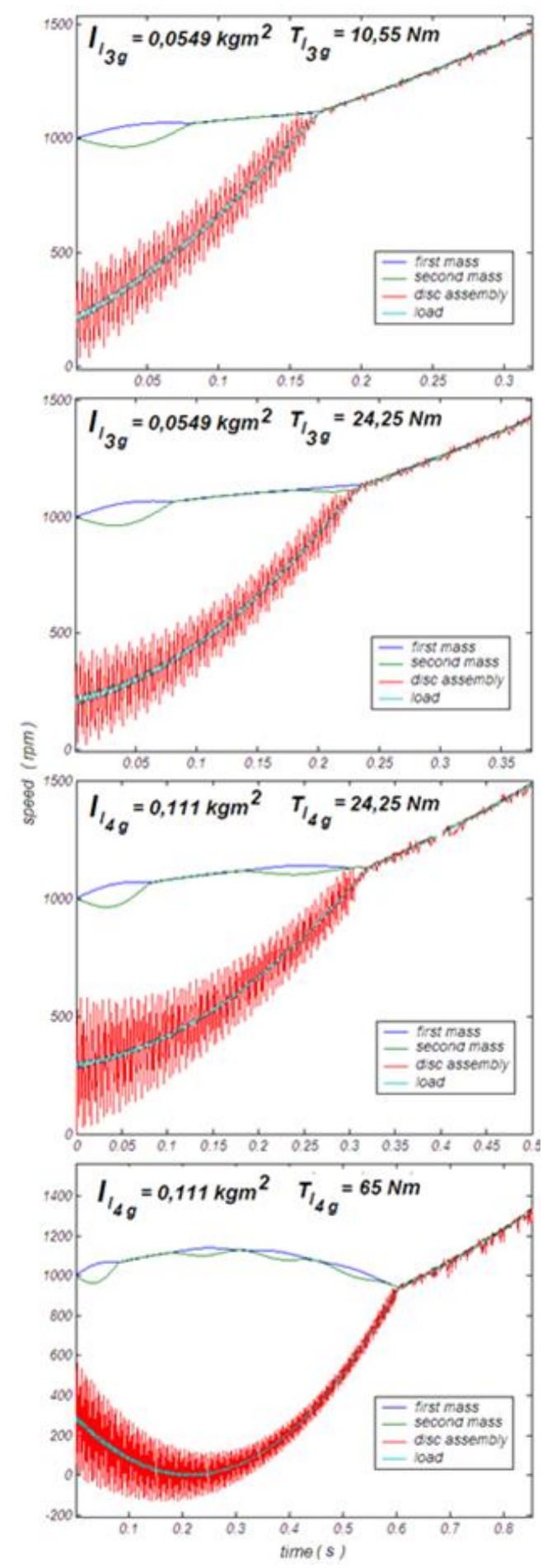

Fig.14. The effect of change in load torque on the clutch dynamic of the system which is used SMF
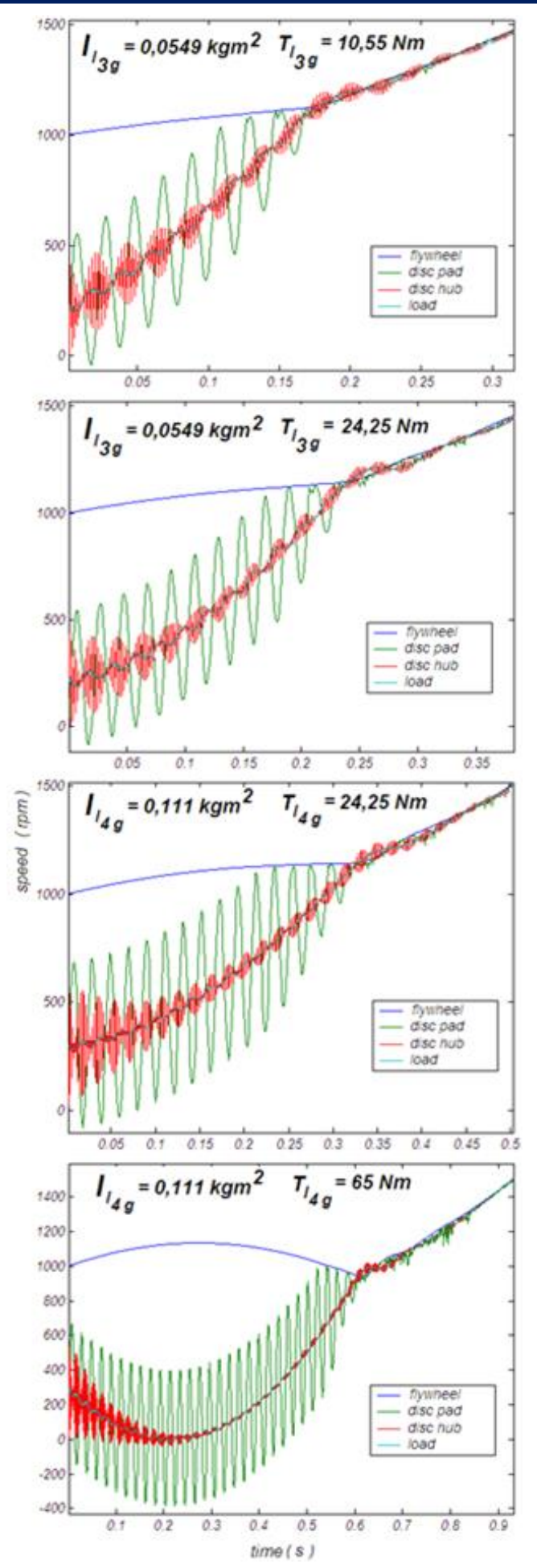

Fig.15. The effect of change in load torque on the clutch dynamic of the system which is used DMF

It is seen that the two-fold increase of load inertia in both systems increases the clutch engagement time by $0,1 \mathrm{sec}$. It is understood that the increase in load inertia is quite effective in the increase of time of clutch engagement. 
When all data are equal except load torque, the changes in the clutch dynamic of the system which is used SMF are seen in Figure 14.

When all data are equal except load torque, the changes in the clutch dynamic of the system which is used DMF are seen in Figure 15.

As seen in the first two graphics in Fig.14 an increase of approximately twice in the load torque for the constant load inertia of $0,0549 \mathrm{kgm}^{2}$ causes an increase of $0,05 \mathrm{sec}$ in the clutch engagement time. In contrast, in the two graphs below an increase of approximately three times in the load torque causes an increase of $0,3 \mathrm{sec}$. of the clutch engagement time in the constant load inertia of $0,111 \mathrm{kgm}^{2}$. It is understood that the increasing of load torque above a certain level increase the clutch engagement time. When is looked to Figure 15, it is seen that this situation expressed for the system with SMF is also valid for the system with DMF.

\section{Conclusions}

It was seen that the dynamic behaviors of both systems have similar and different features. The springs of DMF absorb better the vibrations compared to the disc springs in the conventional system. That's why the speed oscillations which are after the first contact between the elements are less in the system with DMF compared to the system with SMF. The clutch system with DMF operates more smoothly and more regular than the other system. The clutch engagement times of both systems are almost equal and increase due to increasing gear. It was understood that the increase of power transmission system inertia in high gears causes the increase of clutch engagement times. While the small increases of power transmission system load torque change very few the engagement times, the big increases of load torque increase clutch engagement time. As a result, It can be said that the main factor determining the clutch engagement time is the increase in the powertrain inertia rather than the powertrain load moment.

\footnotetext{
Abbreviations

SMF : Single mass flywheel

DMF : Dual mass flywheel
}

\section{References}

[1] Karadere, G., Kopmaz, O. and Güllü, E. (2010). Transient phenomena during engagement phase of a clutch. International Journal of Materials and Product Technology, 39, 3-4, 225-239.

[2] Gaillard, C. L. and Singh, R. (2000). Dynamic analysis of automotive clutch dampers, Applied Acoustics, 60, 399-424.

[3] Sawanobori T. and Suehiro K. (1995). An analysis of clutch judder. Proceedings of SAE 1995 Noise and Vibration Conference and Exhibition, USA, pp. 692696.

[4] Centea, D., Rahnejat, H. and Menday, M. T. (2001). Non-linear multi-body dynamic analysis for the study of clutch torsional vibrations (judder), Applied Mathematical Modelling , 25, 177-192.

[5] Crowther, A., Zhang, N., Liu, D. K. and Jeyakumaran, J.K. (2004). Analysis and simulation of clutch engagement judder and stick-slip in automotive powertrain systems, Journal of Automobile Engineering, 218, 12, 1427-1446.

[6] Jadhav, S. (2014). Powertrain NVH analysis including clutch and gear dynamics. Proceedings of SAE 2014 World Congress and Exhibition, Detroit, Michigan, USA

[7] Güllü, E., Yılmaz, A., Gökdağ, S. (2019). Influence of single and dual mass flywheel usage in IC engines on the resonance behavior of the power transmission system. International Journal of Automotive Science and Technology, 3,4,102-108.

[8] He, L., Xia, C., Chen, S., Guo, J. and Liu, Y. (2019). Parametric investigation of dual-mass flywheel based on driveline start-up torsional vibration control. Shock and Vibration, 1-12 